American Journal of Applied Sciences 7 (6): 811-814, 2010

ISSN 1546-9239

(C) 2010Science Publications

\title{
Injection Molding of Titanium Alloy Implant For Biomedical Application Using Novel Binder System Based on Palm Oil Derivatives
}

\author{
${ }^{1}$ R. Ibrahim, ${ }^{1}$ M. Azmirruddin, ${ }^{1}$ M. Jabir, ${ }^{1}$ M.R. Ismail, ${ }^{1}$ M. Muhamad, \\ ${ }^{2} \mathrm{R}$. Awang and ${ }^{3} \mathrm{~S}$. Muhamad \\ ${ }^{1}$ Advanced Materials Research Centre, SIRIM Berhad, Lot 34, Jalan Hi-Tech 2/3, \\ Kulim Hi-Tech Park, 09000 Kulim, Kedah, Malaysia \\ ${ }^{2}$ Engineering and Process Division, Malaysian Palm Oil Board, No. 6, Persiaran Institute, \\ Bandar Baru Bangi, 43000 Kajang, Selangor Malaysia \\ ${ }^{3}$ Herbal Medicine Research Centre, Institute of Medical Research, Jalan Pahang, \\ 50588 Kuala Lumpur, Malaysia
}

\begin{abstract}
Problem statement: Titanium alloy (Ti6Al4V) has been widely used as an implant for biomedical application. In this study, the implant had been fabricated using high technology of Powder Injection Molding (PIM) process due to the cost effective technique for producing small, complex and precision parts in high volume compared with conventional method through machining. Approach: Through PIM, the binder system is one of the most important criteria in order to successfully fabricate the implants. Even though, the binder system is a temporary, but failure in the selection and removal of the binder system will affect on the final properties of the sintered parts. Therefore, the binder system based on palm oil derivative which is palm stearin had been formulated and developed to replace the conventional binder system. Results: The rheological studies of the mixture between the powder and binders system had been determined properly in order to be successful during injection into injection molding machine. After molding, the binder held the particles in place. The binder system had to be removed completely through debinding step. During debinding step, solvent debinding and thermal pyrolysis had been used to remove completely of the binder system. The debound part was then sintered to give the required physical and mechanical properties. The in vitro biocompatibility also was tested using Neutral Red (NR) and mouse fibroblast cell lines L929 for the direct contact assay. Conclusion: The results showed that the properties of the final sintered parts fulfill the Standard Metal Powder Industries Federation (MPIF) 35 for PIM parts except for tensile strength and elongation due to the formation of titanium carbide. The in vitro biocompatibility on the extraction using mouse fibroblast cell line L-929 by means of NR assays showed non toxic for the sintered specimen titanium alloy parts.
\end{abstract}

Key words: Binder system, rheological study, powder injection molding, debinding and sintered parts

\section{INTRODUCTION}

Titanium and its alloys have become very popular materials because of their low density, high corrosion resistance and excellent mechanical properties (Randall and Animesh, 1997; Liu et al., 2005). Today also the usefulness of titanium for medical implants, for exclusive sporting gears and also for jewelry is recognized. Titanium parts are still expensive not only because of high raw materials prices but also because of difficulty forming, machining and welding. This is why the near net shape forming of titanium is very advantageous. Metal Injection Molding (MIM) as a near net shape process for high production number of small intricate parts is a desirable alternative (Rack and Qazi, 2005).

In the MIM process, the binder is a key component, which provides the powder with the flowability and formability necessary for molding even though it is temporary (Scott Weil et al., 2006). The binder systems that commonly used for injection molding technique were based on thermoplastic materials (Krauss et al., 2007; Witari et al., 2004). In this study, the palm oil derivative which is palm stearin has been formulated

Corresponding Author: R. Ibrahim, Advanced Materials Research Centre, SIRIM Berhad, Lot 34, Jalan Hi-Tech 2/3, Kulim Hi-Tech Park, 09000 Kulim, Kedah, Malaysia 
and evaluated as a possible alternative binder system. The reason for using palm stearin as a binder system is due to its contents that can be advantages during debinding process. It is important that the removal of binder be performed gradually to maintain the shape of the debound part. At different heating temperature, the binder melts leaving different impurities at different melting point. The remaining impurities help forming capillary holes for the removal of the rest of the binder material. Therefore, the selection of palm stearin as a possible alternative binder system fulfills the important criteria of a binder system in PIM process as its components exhibit various melting points.

\section{MATERIALS AND MATHODS}

The morphology of the titanium alloy powder is shown in Fig. 1. It shows that the particle shape of the powder is spherical. This leads to an optimum powder loading in the feedstock between 65-67 volume percent and it is possible to make a good moldings. The mean size of the titanium alloy powder is $25 \mu \mathrm{m}$ were used in the investigation.

Combination of polyethylene and palm stearin was used as the binder system. The binder system comprised $40 \%$ of polyethylene and $60 \%$ of palm stearin (percentage by weight). The powder was mixed with the binder system at $130-160^{\circ} \mathrm{C}$ for $2 \mathrm{~h}$ using $\mathrm{z}$ blade mixer. The feedstock then was studied in term of rheological which is the viscosity and shear rate were measured using capillary rheometer. The vertical injection molding machine was adopted to mold into the tensile test specimen. The green molded specimens were subjected to a solvent extraction step where two third of the binder system was removed. The green molded specimens then were immersed into the heptane for $6 \mathrm{~h}$ at the temperature of $60^{\circ} \mathrm{C}$. The specimen then was continued heated at $10^{\circ} \mathrm{C} \mathrm{min}{ }^{-1}$ up to $1150^{\circ} \mathrm{C}$ under vacuum atmosphere with holding time of $5 \mathrm{~h}$. Figure 2 shows the schematic process of Metal Injection Molding (MIM) technique.

The density of each of the sintered specimen was measured using Densimeter ED-120T. The hardness of the each sintered specimen was measured using Vickers Hardness Tester. The tensile strength of the sintered specimen was measured by Instron Universal Tensile Strength Machine. Optical micrograph was used to observe the microstructure of sintered specimen. The phase of the sintered specimen was measured using XRay Diffraction (XRD). The cytotoxic assay was tested on the extraction of the specimen using mouse fibroblast cell lines by means of NR assays. Meanwhile, the cytotoxic assay on the direct contact assay using Scanning Electron Microscopy (SEM) using L929 cell line was measured after $72 \mathrm{~h}$ of incubation.

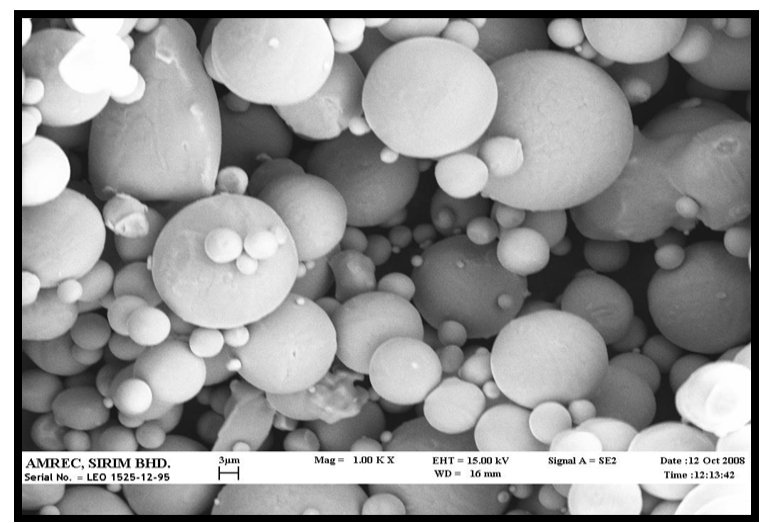

Fig. 1: The morphology of the titanium alloy powder

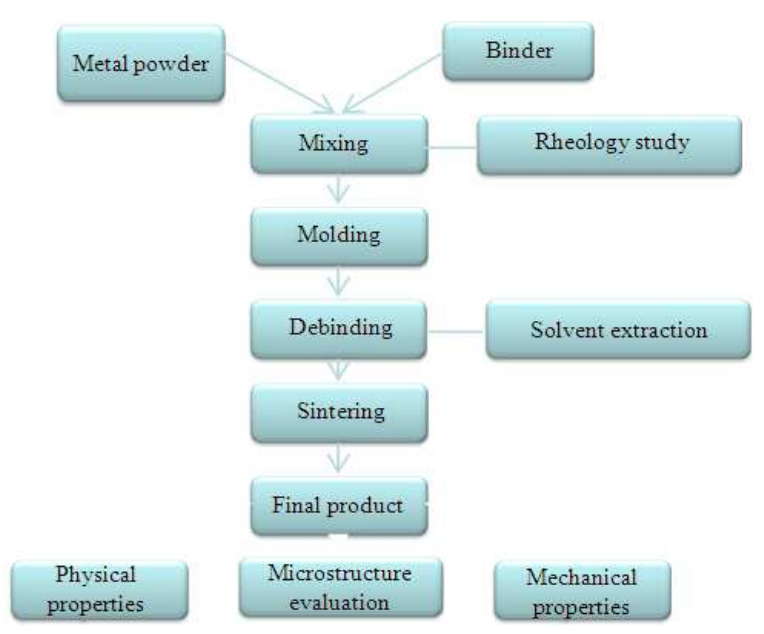

Fig. 2: Shows the schematic process of Metal Injection Molding (MIM) technique

\section{RESULTS}

Rheological study of titanium alloy: Figure 3 shows the viscosity versus shear rate at different temperature of titanium alloy. The graph indicated clearly that as the viscosity decrease the shear rate increase relatively to the increasing of the temperature.

Physical properties of sintered specimen: The physical properties of the sintered specimen titanium alloy parts were shown in Table 1 . The results show that the sintered specimen titanium alloy part have achieved the minimum requirement for sintered PIM parts compared with Standard Metal Powder Industries Federation (MPIF) 35 for the titanium alloy except for the tensile strength and elongation. Microstructure observation using optical micrograph clearly shows the 
crystalline pattern occurred on the sintered titanium alloy parts and shown in the Fig. 4. Figure 5 show the XRD results on the sintered specimen titanium alloy part showing the formation of $\mathrm{TiC}$ (titanium carbide) phase.

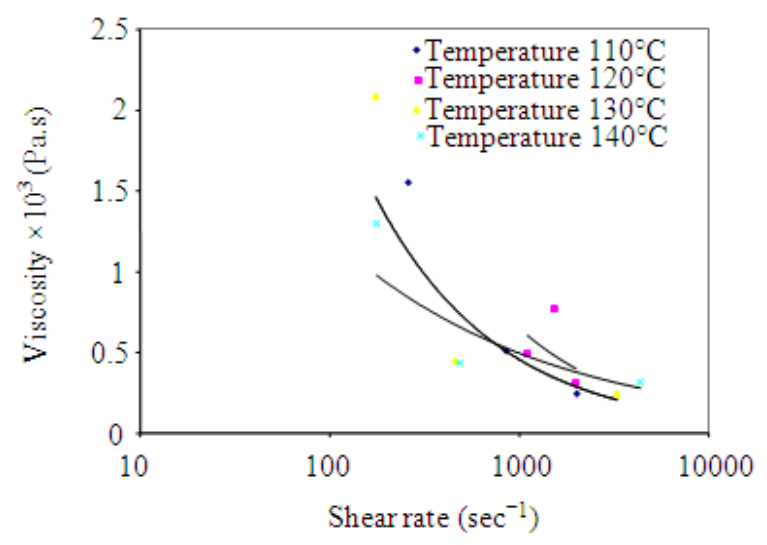

Fig. 3: The viscosity versus shear rate at different temperature of titanium alloy

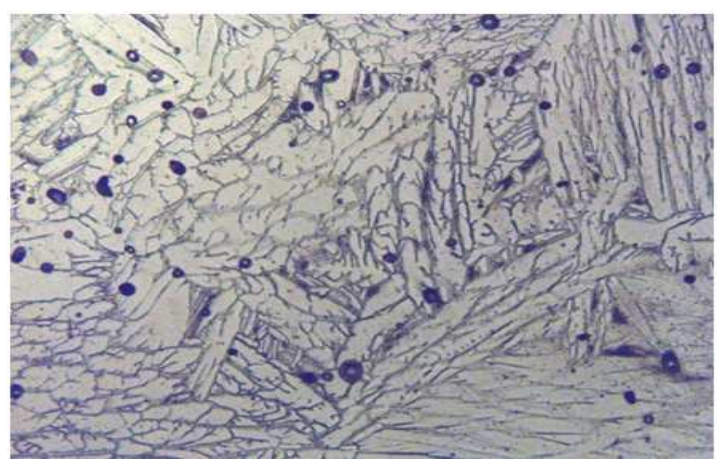

Fig. 4: The micrograph observation of sintered titanium alloy

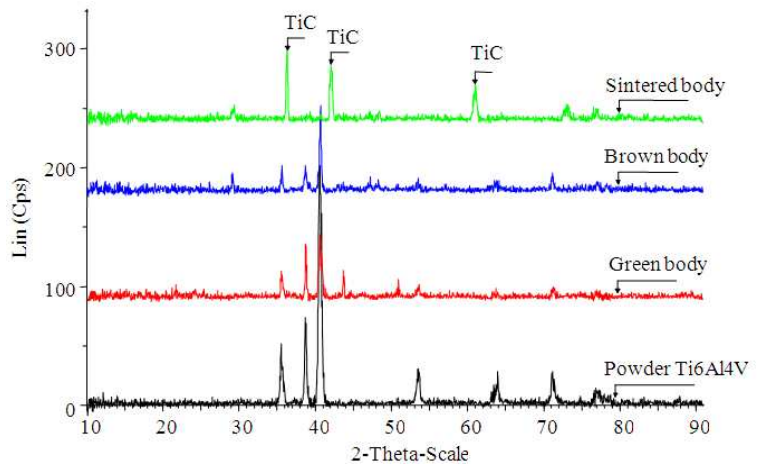

Fig. 5: XRD results on the Sintered Specimen Titanium Alloy

In vitro cytotoxicity study: The cytotoxic assay was tested on the extraction of the specimen using mouse fibroblast cell lines by means of Neutral Red (NR) assays shown in Fig. 6. The results show that the sintered specimen titanium alloy part was non toxic compared with vehicle control. Meanwhile, the cytotoxic assay on the direct contact assay using Scanning Electron Microscopy (SEM) using mouse fibroblast cell lines L929 cell line was measured after $72 \mathrm{~h}$ of incubation. The results show that the image using SEM on the mouse fibroblast cell lines L929 cell line after $72 \mathrm{~h}$ of incubation is completed growth in medium and shown in Fig. 7.

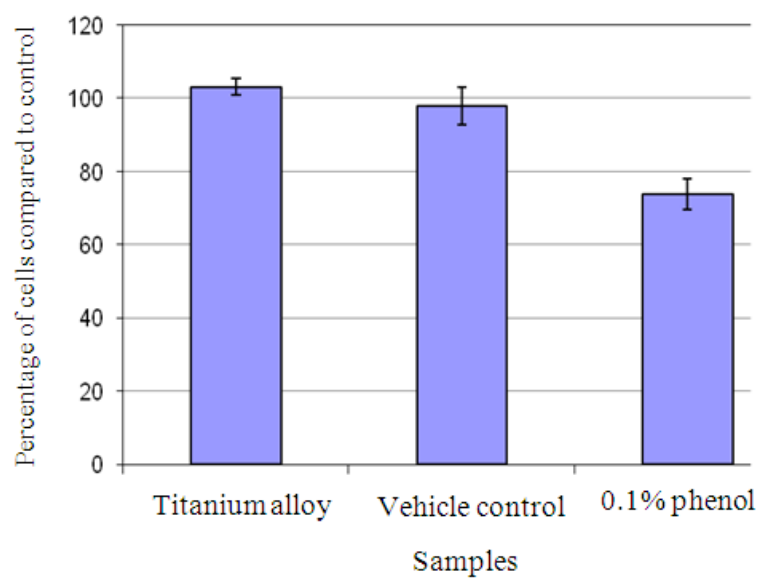

Fig. 6: Cytotoxicity evaluation of titanium alloy produced by PIM using mouse fibroblast cell lines by means of Neutral Red assays

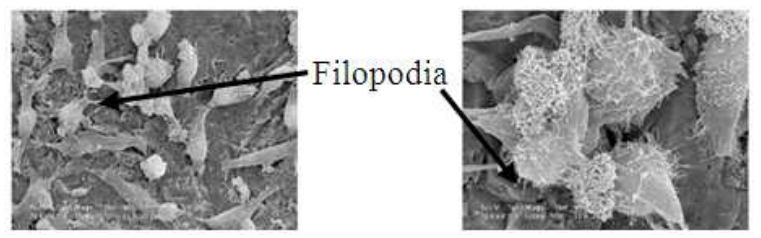

Fig. 7: SEM images of L929 cell line after $72 \mathrm{~h}$ of incubation is completed growth in medium

Table 1: Physical and mechanical properties of sintered titanium alloy

\begin{tabular}{lcl}
\hline Properties & Sintered titanium alloy & MPIF 35 \\
\hline Density $\left(\mathrm{g} \mathrm{cm}^{-3}\right)$ & 4.39 & $>96 \%$ \\
Hardness (Hv) & 381.20 & $300-400$ \\
Porosity (\%) & 2.47 & $<5$ \\
Shrinkage (\%) & 11.86 & $12-15$ \\
Strength (MPa) & 541.53 & $>700$ \\
Elongation (\%) & 0.90 & $10-15$ \\
\hline
\end{tabular}




\section{DISCUSSION}

The feedstock is generally considered to be a pseudoplastic fluid, which indicates a decreasing of viscosity with increase shear rate and temperature. At low temperature the feedstock viscosity is too high for standard molding conditions, while at high temperature results in binder separation that leads to defect of the injected parts. The variation of viscosity versus shear rate in log-log scale graph is almost linear, which is an indicator of feedstock stability. In order to inject the feedstock into injection molding machine, the shear rate and viscosity should be in the range of 100-10000 $\mathrm{sec}^{-1}$ and 1000 Pa.s respectively. The recommended temperature range that can be injected for the titanium alloy feedstock is $110-140^{\circ} \mathrm{C}$.

The physical properties of the sintered specimen titanium alloy parts have achieved the minimum requirement for sintered PIM parts compared with Standard Metal Powder Industries Federation (MPIF) 35 for the titanium alloy except for the tensile strength and elongation properties. These phenomena occurred due to the formation of $\mathrm{TiC}$ (titanium carbide) phase which is affected on the strength and elongation of the sintered titanium alloy parts. This has been proven on the XRD results shown in Fig. 5, the existing of TiC on the sintered titanium alloy parts. The microstructure observation using optical micrograph clearly shows the crystalline pattern structure due to the formation of beta ( $\beta$ ) grain and alpha/beta $(\alpha / \beta)$ lameallae structure on sintered titanium alloy and shown in the Fig. 4

The cytotoxic assay on the extraction of the sintered specimen titanium alloy parts using mouse fibroblast cell lines by means of NR assays show the non toxic compared with vehicle control. The growth of mouse fibroblast cell lines L-929 has been successfully attached and proliferated with numerous filopodia on the surface of sintered specimen titanium alloy. The morphology on the surface also showed the rounded cells indicating that the cells in mitosis.

\section{CONCLUSION}

The feedstock of using palm stearin as a binder system is suitable for injection molding machine, the shear rate and viscosity of the feedstock is in the range of 100-10000 sec ${ }^{-1}$ and 1000 Pa.s respectively. The physical and mechanical properties of the sintered titanium alloy part have achieved the minimum requirement for sintered MIM parts were compared with the Standard Metal Powder Industries Federation (MPIF) 35 for titanium alloy except for the strength and elongation due to the formation of TiC. The cystallinity structure of titanium alloy was shown clearly on the micrograph. The in vitro biocompatibility on the extraction of the sintered specimen titanium alloy parts using mouse fibroblast cell line L-929 by means of NR assays show non toxic.

\section{ACKNOWLEDGEMENT}

This study partly was supported by Techno Fund of MOSTI (TF0206D124) and Advanced Manufacturing Research Institute (AMRI), Advanced Industrial Science and Technology (AIST), Japan.

\section{REFERENCES}

Krauss, V.A., A.A.M Oliveira, A.N. Klien, H.A. AlQureshi and M.C. Fredel, 2007. A model for PEG removal from alumina injection molded parts by solvent debinding. J. Mater. Process. Technol., 182: 208-273.

Liu, Y., L.F. Chen, H.P. Tang, C.T. Liu, B. Liu and B.Y. Huang, 2005. Design of powder metallurgy titanium alloy and composites. Mater. Sci. Eng. A., 418: 25-35.

Rack, H.J. and J.I. Qazi, 2005. Titanium alloy for biomedical application. Mater. Sci. Eng. C, 26: 1269-1277.

Randall, M.G. and B. Animesh, 1997. Injection Molding of Metal and Ceramics. MPIF, Princeton, New Jersey, USA., ISBN: 1-878-954-61-X.

Scott Weil, K., E. Nyberg and K. Simmons, 2006. A new binder system for powder injection molding titanium and other reactive metals. J. Mater. Process. Technol., 176: 205-209.

Witari, F., A. Yokoyama, M. Omori, T. Harai and H. Kondo et al., 2004. Biocompatibility of materials and development to functionally graded implant for bio-medical application. Compos. Sci. Technol., 64: 893-908. 